\title{
ОБРАЗ ОТЦА В ПРОИЗВЕДЕНИЯХ И В ЖИЗНИ ВИЛЬЯМА И АРАМА САРОЯНОВ
}

Епремян Л.К. (Ереванская государственная консерватория имени Комитаса,

Ереван. Армения)

mikaelterlemez@gmail.com

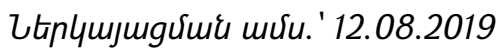

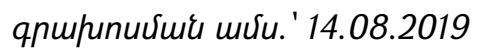

цищшаппьрјшй цйппиичши шй. ' 19.08.2019

В статье с позиций психоанализа прослежена проблематика сложных взаимоотношений отца и сына Сароянов, Вильяма и Арама, которая нашла отражение в их литературных произведениях - «Dier Baby», «Mama I Love You», "Papa You're Crazy», «My Name Is Aram», «Brief to Armenak from Bitlis» и др. В. Сарояна и «Last Rites: The Death of William Saroyan» Арама Сарояна. Психоанализ впервые актуализовал проблему трансгенерационной травмы. Травма геноцида армян по-разному проявилась в представителях двух поколений одной семьи, став главной причиной их взаимного отчуждения. Мистический «призрак» отца Арменака в сознании Вильяма, постоянное ожидание возвращения идеального Отца, его идентификация с сыном Арамом и невозможность соединения образа Отца и не соответствующего его ожиданиям сына Арама приводят к конфрликту длиной в целую жизнь героев.

Ключевые слова: трансгенерачионная травма, психоанализ, Вильям Сароян, Арам Сароян, Эдвард Мирзоян.

«Сто лет одиночества» - так была озаглавлена статья в газете «Новое Время» [6], где в моем переводе на русский был опубликован газетная, краткая версия мемуаров Арама Сарояна об отце, «Last Rites: The Death of William Saroyan».

Шел 1999 год, когда я только начинала работать над монографией о композиторе Эдварде Мирзояне [1]. Именно ему я показала недавно выпущенную книгу с воспоминаниями Арама о Вильяме Сарояне. Эдвард Михайлович был потрясён. Он попросил меня купить ещё две книги, одну себе, другую, надписав, подарил мне в память о первых днях совместной работы. Именно эта книга предопределила весь ход моего исследования о композиторе, которое выполнено не в традиционно музыковедческом, а в междисциплинарном формате с использованием психоаналитического метода. Тема отца оказалась крайне болезненной для Эдварда Мирзояна, который на девятом десятке жизни впервые решился откровенно рассказать о своей настоящей фамилии, об отце, Семене Алиханове, о сложных, нестерпимо болезненных с ним отношениях, о чрезвычайно сильном влиянии матери, которая категорически запретила свидания с отцом, о 
травме, передавшейся через поколения сыну и внукам, о том, как сейчас он пересматривает свою позицию и признает свою вину в отказе от своих корней и в том, что уже никогда не найдёт могилы отца. Откровения подобного рода не просто не встречаются в отечественном музыкознании - любой факт, касающийся проблем личного характера музыканта, категорически табуирован. Представителей старшего поколения музыковедов это коробит так, что доктор-профрессор Светлана Саркисян по поводу моей статьи в одном из московских научных журналов [2] уже после смерти Мирзояна в разговоре с вдовой композитора назвала «позором» тот факт, что Микаэл Мирзаян назван отчимом Эдварда Михайловича, а не отцом, как неверно указывалось ранее в биографических источниках. Поэтому, зная подобную установку общества, нужно по достоинству оценить масштаб личности композитора, который, презрев все привычные ограничения, решился не просто высказаться, а выступить с обвинениями, направленными против самого себя в молодом и зрелом возрасте и - чтимой им выше всех святых - матери. Это первое публичное признание ошибки Люси Богдановны, уничтожившей биологического отца в сознании сына, первое преодоление - в 80 лет! непререкаемого родительского авторитета матери. Скрипач Эдуард Тадевосян признавался: «Эдик боготворил мать - ни при каких условиях она не могла оказаться не права, ее желание - закон. Честно говоря, я бы не удержался, хотя и мягко, но возразил бы, что, скажем, в этом вопросе думаю иначе. Для Эдварда Михайловича это [было] невозможно - меня это всегда поражало» [1, 131]. Мать была и оставалась для него высшим непререкаемым авторитетом, который при ее жизни так и не был, низвергнут с пьедестала родительского императива. Всегда и в 5, в 40, и в 70 лет - Эдик оставался для нее все тем же ребёнком, которого нужно было наставлять и вести по этой нелёгкой жизни.

И только в моей монографии все иначе. Мирзоян для твёрдости духа даже счёл нужным продиктовать мне расписку-обязательство со следующим текстом: «(арм.)Ты автор книги и должна писать так, как решишь сама. (русск.) Даже если меня будет что-то шокировать, все равно надо помнить, что ты хозяин книги. Хотя не моя хозяйка» (архив Л. Е.).

Однако обратимся к самому источнику - «Last Rites: The Death of William Saroyan» Арама Сарояна, к воспоминаниям о последних днях жизни его отца.

37-летний сын Вильяма Сарояна выступает здесь не просто мемуаристом, но и в некотором роде психоаналитиком, который искренне пытается понять отца, вникнуть в суть его проблем, обнажить истоки так и не преодолённого конфрликта между Вильямом и его семьёй: женой, дочерью и сыном. Арама Сароян справедливо подчёркивает, что Вильям в раннем детстве, в 3 года, пережил смерть отца, которая, наступила от разрыва слепой кишки, согласно семейному мифу, спровоцированного стаканом воды. Арменак выпросил у жены воду, а пить, ему было категорически запрещено. Фигурально выражаясь, Арменак Сароян принял смерть из рук своей 
жены, а она, оставшись без мужа, сдала детей в сиротский приют и с тех самых пор, считает Арам, женщина и смерть слились в сознании Вильяма в неразрывное целое. Вот как Арам описывает детскую травму своего отца, лишённого родительской любви и ласки и проявлявшего высокую степень депривации7:

«Из 72 лет 69 его окружала злость, теперь он умирает, но яд этот все ещё внутри и, более того, он ещё более действенен. [...] Это похоже на сказку. Озеро в душе ребёнка преображается в зеркало - и рождается писатель, достигший всемирного признания. Но внутри все же остаётся жёсткое заледенелое стекло...И вот он влюбляется, и лёд этот снова растоплен. Любовь вывела из власти холода этого знаменитого человека, который до того не знал ее великой силы. Любовь врывается в его душу, зеркало вновь преображается в гладь озера, и он кричит от болезненности этой метаморфозы. Он ненавидит свою жену, оттого что любит ее. А потом ненавидит дочь и сына. Поскольку в озере его души властвует Смерть - жуткая смерть отца. А позже, в три года, когда его поместили в сиротский приют, - и кажущаяся смерть матери. Он ненавидит свою жену, потому что любит ее, а она, ещё слишком юная, не знает, какую ошибку совершила и чем могла вызвать подобный гнев мужа. Но сколько бы она, мудрея с годами, ни старалась ему угодить, все равно ей не достичь успеха. Потому что единственный способ для отца любить ее - ненавидеть» [8, 391].

Отрицательный Эдипов комплекс, с точки зрения сына, абсолютно объясняет поведение отца, который дважды по любви женившись на одной и той же женщине, так и не смог построить позитивных семейных отношений ни с Кэрол, ни с Арамом, ни с дочерью Люси.

Однако Арам Сароян, который носит фамилию отца, в своих интерпретациях практически не принимает во внимание истинной причины страданий, главной проблемы в жизни и творчестве писателя: трансгенерационной травмы Геноцида армян. И, по большому счету, не только не идентифицирует себя с носителями этой травмы, армянами, но в определённой мере противопоставляет себя им, принимая сторону матери. «В первый период брака моих родителей после очередного конфликта с моей матерью он бежал к армянам, которые встречали его с распростёртыми объятиями и успокаивали, даря ему царский трон и жезл. Они удивлялись, как можно так жестоко, как эта девушка - к тому же не армянка, а еврейка, обходиться с этим чудесным человеком. [...] И спустя какое-то время, он влюбился в то, что не причиняло ему столько боли. [...] Сароян влюбился в СЛАВУ» [8, 392].

Что же является очевидным доводом в пользу такого умозаключения сына? Хотя бы строки из романа отца «Не умерать» («Not Dying», 1963): «Единственный человек, которого я действительно любил - это Сароян, и все, что сейчас действительно люблю - то, что ещё осталось во мне от Сарояна» [8, 392]. Фраза,

\footnotetext{
7 Несколько пространные и частые цитаты необходимы для представления более широкой клинической картины конкретного психологического исследования.
} 
которая в толковании Арама предстает как бесспорное, очевидное доказательство крайней степени самовлюблённости и эгоцентризма отца. А на самом деле, в ее глубинном понимании, свидетельствует о неизбывной тоске по несостоявшемуся образу самого себя, по уникальному и уже утерянному аборигенному типу западного армянина, по Роду Сароянов, по всему, что писателю удалось сохранить в себе от отца Арменака, армянских предков и своего мифологизированного Отечества. «Бывало иногда, что по ночам я вскакивал во сне от потрясения, будто от смерти, пытаясь осмыслить происходящее, задаваясь вопросами: “Но как же так, где это я? где мой народ? где мой отец? где мой сын?” Потом, постепенно приходя в себя, я понимал все то, что должно быть понятно каждому, вставал с постели, закуривал сигарету, наливал бокал виски, втягивал в себя дым, глотал спиртное и отдавался во власть своих дум» $[9,324]$.

Перед нами клиническая картина маргинала (термин американского социолога Р. Парка) [4, с.172-173 ], то есть «чужака», который обречён на существование сразу в двух местах, он здесь и, одновременно, не здесь, он разрывается на части, ощущая себя битлисцем, сыном Арменака, и Вильямом, отцом Арама, когда последнему чуждо острое ощущение потерянной Родины - Армении. Ощущение пребывания «сразу в двух местах» описано, например, в книге Вильяма Сарояна «Меня зовут Арам», когда армянская семья Гарогланянов в США продолжала существовать по законам и традициям потерянной родины: «Нам казалось, что мы пока ещё в старом Эргире, то есть, как говорили [указывали] нам соседи, там, где и есть наше [истинное] место» [10, 7-8].

Необходимое условие маргинализации - различие норм, ценностей, представлений, моделей поведения в тех группах, между которыми человек оказывается. Если в условиях старой семейной системы фригура Отца обладала непререкаемым авторитетом и правом вести по жизни детей, независимо от их возраста, то в новой нормативной системе представлений любое замечание в адрес сына или дочери воспринимается как нарушение границ их личного жизненного пространства, навязчивое внедрение в зону индивидуальной ответственности личности и, в конечном итоге - жестокое насилие по отношению к собственным детям. Именно так Арам воспринимает назидательное письмо отца после произошедшей с ним автомобильной катастрофы, где писатель стыдит сына за то, что тот, уверен отец, употребляет наркотики и садится за руль в состоянии наркотического опьянения, после чего Арам порывает все контакты с отцом на долгие годы, при этом не отрицая своей вины. Точно так - как личное оскорбление, - воспринимает Люси череду так называемых «упрёков» на повышенных тонах, когда умирающий от рака Вильям Сароян, страдая от неустроенности дочери, винит ее в том, что не сумела найти своё место в этой жизни, не смогла построить ни семьи, ни карьеры. В то время как для традиционной армянской семьи назидательная речь подобного рода свидетельствует только об одном - о крайней степени беспокойства отца за судьбу 
любимой дочери. «Ты пришла, чтобы побыть рядом с великим писателем», бросает он в сердцах Люси, красавице, так похожей на жену, как бы сошедшую с обложек голливудских журналов. Источая запах духов, непереносимый для обречённого старика, она простодушно, от чистого сердца привезла целую корзину еды и курочку в придачу доживающему последние дни отцу, который не в состоянии выпить даже сока. «Хватит! - кричит обессиленный старик дочери, оскорблённой до слез, - забери все и убирайся отсюда!» [5] По накалу страстей и драматизму эта картина последней, как кажется, встречи любящих друг друга людей достойна пера Шекспира...

Драматичен до крайности и образ осиротевшего ребёнка, который каждую минуту ждёт возвращения родного отца, отказываясь верить в его смерть. Это свое ощущение, с годами то более интенсивное, то несколько угасающее, Вильям Сароян описывает в одном из «Писем с улицы Тойнби 74», адресованному умершему 55 года назад отцу, Арменаку из Битлиса. «Как маленький мальчик, который усиленно пытается понять положение вещей в этом мире, я верил, что совсем скоро, в один из дней, ты, проходя по улице, направишь свои шаги прямо ко мне, точно зная, что я твой трёх-. четырёх-, пяти-, шести-, семи- или восьмилетний сын. [...] Мой отец, - размышлял я, - должен сделать это, ведь он мой отец: он не может исчезнуть в небытии лишь оттого, что умер, он найдёт чудный способ вновь восстать из мёртвых, подняться на ноги и, прошагав путидороги, придёт и найдёт своего сына по той простой причине, что он мой отец. Таким, как мы, под силу это, даже если известно, что такое невозможно, что это противоречит законам природы, но мой отец сделает это, и что тогда подумает весь мир? Что скажут на это люди? Они скажут: “Он десять лет был мёртв, а затем вернулся. Вернулся таким же, каким и был - не призраком, не привидением, не в образе кого-либо похожего на себя - вернулся сам, чтобы своими устами произнести имя сына"» [9, 322-323]. Отец - Отечество - Fatherland - Битлис сливаются в сознании Вильяма Сарояна, как “заколдованное место и время, в котором отец писателя остаётся [вечно]живым” [3].

С рождением сына в сознании писателя происходит абсолютное наложение образов отца Арменака и сына Арама. Не поиск общих черт: формы рта, носа или, скажем, родинки, что естественно, а полное совпадение, практически реинкарнация отца через акт рождения сына, и в этом случае детская позиция ожидания чуда, возвращения отца писателя перерождается в инфантильную позицию требования отцовской любви, защищённости и безопасности... от новорождённого сына: «Это он. И скоро я увижу его идущим по улице, он остановится и заговорит со мной, точь-в-точь так, как я и представлял, что он сделает это. Этот всего восемь или чуть более часов назад родившийся старец - мой папа» [9, 323] И когда однажды в Нью-Йорке писатель издали замечает идущего навстречу в толпе 15-летнего сына, он не окликает его, а только ждёт, что сын-отец первым произнесёт его имя... 
Ведь кто чей отец? - размышляет Вильям, развивая известную ему теорию о том, что каждый в этом мире приходится отцом другому. Что-то похожее на «все мы от Адама и Евы». Но сам он предпочитает быть сыном, которому навстречу выйдет Отец или Сын-Отец, который никогда не умирал, причём писатель вполне осознает свою проблему как «почти психопатическое стремление возвращаться в прошлое» $[7,135]$. В этом непростом клубке взаимоотношений главным мотивом является отчуждение Вильяма Сарояна, который по стечению трагических обстоятельств начала XX века - изгнания и геноцида аборигенного населения Эргира, то есть Западной Армении, - находится в болезненном бесконечном поиске самого себя, своего метафизического Дома-Битлиса [5] и Отца - символов невозвратимой потери целого народа.

Работая с вышеприведёнными литературными источниками, мы имеем дело с уникальным материалом исследования, когда акт художественного творчества становится показательным актом самоанализа автора, и где жизнь перерастает не в художественный вымысел, а в ещё более глубокое постижение истинных жизненных смыслов реальности. Под влиянием психоанализа Фрейда сформировался новый жанр - психобиография. Его можно рассматривать как автобиографический роман души героя, почти исповедь, внутренний диалог с самим собой, анализ скрытых явлений на суд читателей. Именно такой путь - от глубокого личного опыта самоанализа к познанию другого и завещал Фрейд. И это, с моей точки зрения, самая точная характеристика всего творчества Вильяма Сарояна.

\section{Литература}

1. Епремян Л. Эдвард Мирзоян в письмах и диалогах. Ер., 2011, 616 с.

2. Епремян Л. Судьбоносный выбор (к проблеме осмысления векторов развития армянской музыки XX века). // Журнал «Научный вестник Московской консерватории», М., 2015, №3, с. 194-205.

3. Олюнина В., Меликсетян Л.: Битлис как концепт в творчестве У. Сарояна.// Новостной портал Армянского музея Москвы и культуры наций, 3 ноября 2017, www.armmuseum.ru/news-blog/2017/11/2/--2.

4. Парк Р. Культурный конфликт и маргинальный человек. // «Реферативный журнал», 1998, №2, серия 11, «Социология», с.172-173.

5. Сароян У. Битлис. // в кн.: У. Сароян. Случайные встречи. М., «Известия», 1986.

6. Сто лет одиночества (Сароян А. Последние сцены, подготовила Л. Епремян), газета “Новое Время", 16 декабря 1999 г.

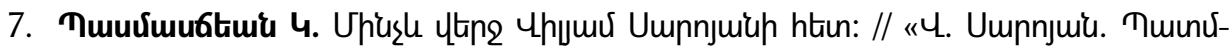

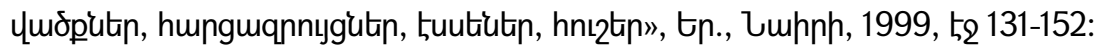

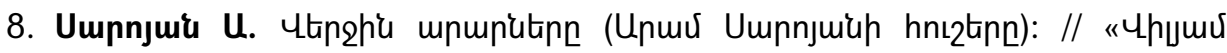

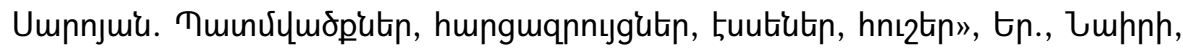
1999, to 385-420: 


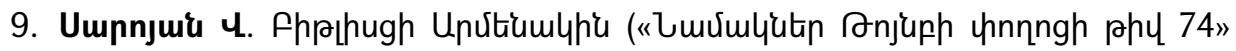

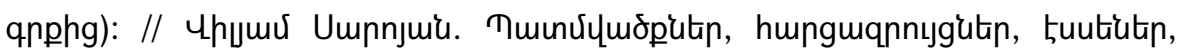
hnı2tin, tn., 乙uphn, 1999, t52 321-326:

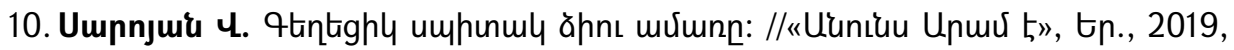
"Uiununtiu», to 3-15:

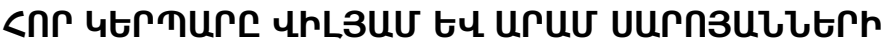

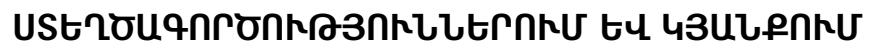

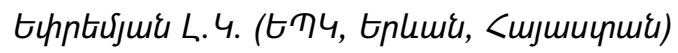

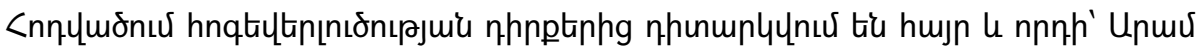

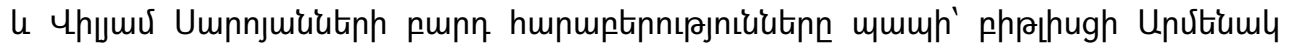

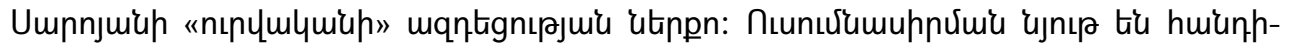

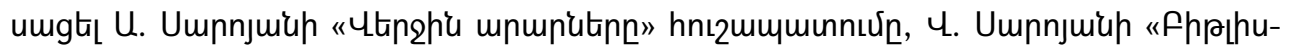

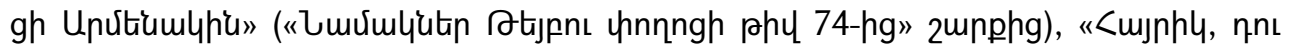

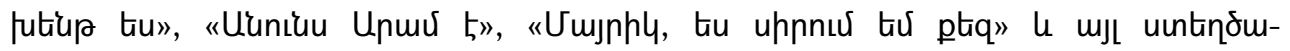

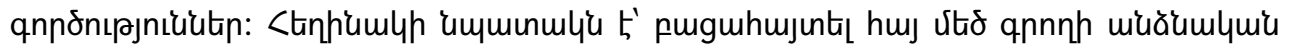

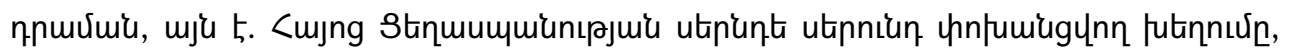

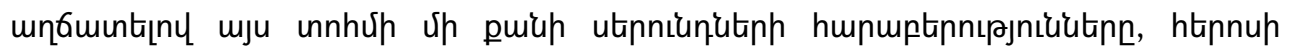

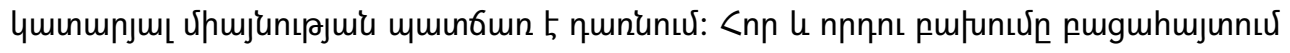

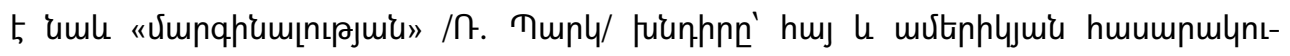

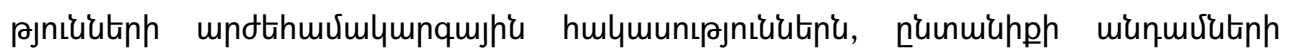

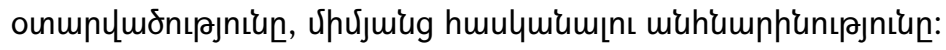

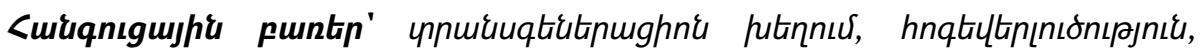

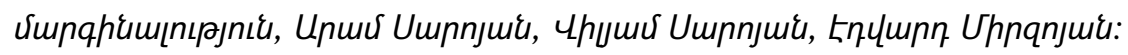

\section{THE CHARACYER OF FATHER IN THE WORKS AND LIFE OF WILLIAM AND ARAM SAROYAN}

Yepremyan L.K. (Yerevan State Conservatory, Yerevan, Armenia)

The article considers the complicated relationship between the father and the son, William and Aram Saroyan influenced by the "ghost" of grandfather, Armenak Saroyan of Bitlis, in the view of psychoanalysis. The studied material's the memoir by A.Saroyan named "The Last Rites", "Armenak of Bitlis"(from "Letters from 74 rue Taitbout") and "Papa You're Crazy" by W.Saroyan. The purpose of the author is to expose the personal drama of the great Armenian writer that is the intergenerational transmission of the trauma caused by the Armenian Genocide. Orphaned at an early age, William shifts onto his newborn son's shoulders the expectations from the "ghost" of his dead father following him, thus making it impossible to form and assert his paternal position.

Kaywords: transgenerational trauma, psychoanalysis, Aram Saroyan, William Saroyan, Edvard Mirzoyan. 